\title{
Oxidative stress in electrohypersensitivity self-reporting patients: Results of a prospective in vivo investigation with comprehensive molecular analysis
}

\author{
PHILIPPE IRIGARAY ${ }^{1,2}$, DANIELA CACCAMO ${ }^{3}$ and DOMINIQUE BELPOMME ${ }^{1,2,4}$ \\ ${ }^{1}$ Association for Research Against Cancer (ARTAC), 75015 Paris, France; ${ }^{2}$ European Cancer and \\ Environment Research Institute (ECERI), 1000 Brussels, Belgium; ${ }^{3}$ Department of Biomedical Sciences, \\ Dental Sciences and Morpho-Functional Imaging, Polyclinic Hospital University, I-98122 Messina, Italy; \\ ${ }^{4}$ Department of Clinical Research, Paris V University Hospital, 75005 Paris, France
}

Received April 17, 2018; Accepted July 6, 2018

DOI: $10.3892 / \mathrm{ijmm} .2018 .3774$

\begin{abstract}
A total of 32 electrohypersensitivity (EHS) self-reporting patients were serially included in the present prospective study for oxidative stress and antioxidative stress response assessment. All thiobarbituric acid-reactive substances (TBARs) were measured in the plasma, particularly malondialdehyde (MDA) for lipid peroxidation; additional measurements included total thiol group molecules, reduced glutathione (GSH), oxidized glutathione (GSSG) for oxidative stress assessment and nitrotyrosine, a marker of peroxynitrite-induced oxidative/nitrosative stress. In addition, the activity of $\mathrm{Cu}-\mathrm{Zn}$ superoxide dismutase (SOD1) was measured in red blood cells (RBCs) and glutathione reductase (GR) and glutathione peroxidase (GPx) in RBCs and plasma. Depending of the biomarker considered, 30-50\% of EHS self-reporting patients presented statistically significantly increased TBARs, MDA, GSSG and NTT mean plasmatic level values in comparison with normal values obtained in healthy controls $(\mathrm{P}<0.0001)$. By contrast, there were no plasmatic level values above the upper normal limits for GSH, GSH/GSSG ratio, total
\end{abstract}

Correspondence to: Professor Dominique Belpomme, Association for Research Against Cancer (ARTAC), 57/59 rue de la Convention, 75015 Paris, France

E-mail: contact.belpomme@gmail.com

Abbreviations: CFS, chronic fatigue syndrome; EHS, electrohypersensitivity; EMFIS, electromagnetic fields intolerance syndrome; GluT, total glutathione; GPx, glutathione peroxidase; GSH, reduced glutathione; GR, glutathione reductase; GSSG, oxidized glutathione; MCS, multiple chemical sensitivity; MDA, malondialdehyde; NTT, nitrotyrosine; RBC, red blood cells; SOD1, $\mathrm{Cu}-\mathrm{Zn}$ superoxide dismutase; TBARs, thiobarbituric acid-reactive substances

Key words: EHS, electromagnetic fields, EMFIS, glutathione, inflammation-associated biomarker, malondialdehyde, nitrotyrosine, oxidative stress, SOD1 glutathione (GluT) and GSH/GluT ratio, and values for these GSH-associated biomarkers were statistically significantly decreased in $20-40 \%$ of the patients $(\mathrm{P}<0.0001)$. Furthermore, in RBCs, mean SOD1 and GPx activities were observed to be statistically significantly increased in $\sim 60 \%$ and $19 \%$ $(\mathrm{P}<0.0001)$ of the patients, respectively, while increased GR activity in RBCs was observed in only $6 \%$ of the patients. The present study reports for the first time, to the best of our knowledge, that overall $\sim 80 \%$ of EHS self-reporting patients present with one, two or three detectable oxidative stress biomarkers in their peripheral blood, meaning that these patients-as is the case for cancer, Alzheimer's disease or other pathological conditions-present with a true objective new pathological disorder.

\section{Introduction}

Electrohypersensitivity (EHS) is a new World Health Organization (WHO)-acknowledged disabling condition occurring in EHS self-reporting patients (1).

Following the WHO-sponsored international workshop on electromagnetic hypersensitivity in 2004 in Prague (Czech Republic) the use of the term 'idiopathic environmental intolerance (IEI) attributed to electromagnetic fields (IEI-EMF)' was proposed to qualify this new EHS-associated detrimental health condition (2).

Using ultrasonic cerebral tomosphygmography (UCTS), it was recently demonstrated that EHS self-reporting patients present with a decrease in mean cerebral tissue pulsation index (PI) in a number of areas of the temporal lobe, particularly in the capsulo-thalamic area, which contains the limbic system and the thalamus; it was additionally suggested that these abnormalities may in fact be associated with a decrease in brain blood flow and/or neuronal dysfunction in these particular brain areas (3-5). EHS self-reporting patients were also objectively identified and characterized by demonstrating potential associations with a number of biological abnormalities, consisting of a degree of inflammation, heat-shock protein-associated cellular stress and autoimmune responses in the peripheral blood, and an abnormal 6-hydroxy-melatonin 
sulfate/creatinine ratio in the urine (3). In fact, since it was reported that numerous EHS self-reporting patients present reliable clinical symptoms each time they report exposure to electromagnetic sources, and present with objective UCTS and biological abnormalities $(4,5)$, the authors of the present study proposed the use of the more concise term electromagnetic field intolerance syndrome (EMFIS) to qualify the so-called newly WHO-recognized IEI-EMF pathological condition with which these patients are associated (4).

The present prospective in vivo biochemical investigation aimed to determine whether EHS self-reporting patients may also be characterized by oxidative stress abnormalities in the peripheral blood, to further identify and characterize EMFIS.

\section{Materials and methods}

Inclusion criteria. According to a previous study (3), EHS, more precisely EMFIS in EHS self-reporting patients, was defined on the basis of the five following clinical criteria: i) Absence of known pathology accounting for the observed clinical symptoms; ii) as reported by the patients, reproducibility of symptoms under the supposed influence of electromagnetic fields (EMFs), regardless of the incriminated source; iii) regression or disappearance of symptoms associated with reported EMF avoidance; iv) clinical symptoms compatible with those previously ascribed to EHS self-reporting patients in the scientific literature; and v) chronic evolution (6-10).

Prior to inclusion, all patients had a face-to-face interview based on a previously validated questionnaire, a complete general and neurological clinical examination and a systematic biological check-up, including currently used peripheral blood tests, to exclude any non-EMFIS-associated pathology. Therefore, to be included in the study, patients had no history of such pathologies as cancer, Alzheimer's disease, diabetes type II and/or cardiovascular disease. Patients also had no associated multiple chemical sensitivity (MCS), and were in an active symptomatic phase of their pathological condition(s), whether or not they had been previously treated. In addition, patients had a normal carotid and vertebral artery echodoppler scan, normal hematological, hepatic, renal and metabolic peripheral blood tests, and, when available, a normal magnetic resonance imaging or computed tomography scan.

However, since the majority of clinical symptoms in EHS self-reporting patients are subjective, two biological inclusion criteria were added to objectively identify EMFIS: i) A mean decreased tissue pulsometric index in at least three middle cerebral artery-dependent tissue sections in the temporal lobes, as demonstrated using UCTS, as it has been previously reported that UCTS is able to discriminate between EHS self-reporting patients and healthy subjects using this criterion (11); and ii) an increase in at least one of three inflammation-associated peripheral blood biomarkers that have previously been identified as being possibly detected in EHS self-reporting patients (3): Increased histamine, a mediator of inflammation (12); increased protein S100B, a marker of oxidative stress-associated blood brain barrier opening $(13,14)$; and increased chaperone proteins heat shock protein $\beta 1$ (HSP27) or heat shock $70 \mathrm{kDa}$ protein $1 \mathrm{~B}$ (HSP70), markers of heat-shock cell stress-associated inflammation and/or immune response $(15,16)$. References for the
Table I. Inflammation-associated biomarkers investigated in electrohypersensitivity self-reporting patients.

\begin{tabular}{llcc}
\hline Author, year & Biomarker & Sample type & (Refs.) \\
\hline Lebel et al, 1996 & Histamine & Plasma & $(17)$ \\
Smit et al, 2005 & Protein S100B & Serum & $(18)$ \\
De and Roach, 2004 & HSP27 & Serum & $(19)$ \\
Pockley et al, 1998 & HSP70 & Serum & $(20)$ \\
\hline
\end{tabular}

HSP27, heat shock protein $\beta 1$; HSP70, heat shock $70 \mathrm{kDa}$ protein $1 \mathrm{~B}$.

methods used to measure these three inflammation-associated peripheral blood biomarkers are indicated in Table I (17-20).

Oxidative and antioxidative stress-related biomarkers. A battery of biomarkers were used to measure oxidative stress and antioxidative stress responses, in plasma and/or red blood cells (RBCs) (Table II). Measurements were performed following centrifugation $\left(4,000 \mathrm{x} \mathrm{g} ; 10 \mathrm{~min} ; 4^{\circ} \mathrm{C}\right)$ to separate RBCs from plasma.

Oxidative stress biomarkers. For oxidative stress assessment, the following biomarkers were measured in the plasma: All thiobarbituric acid-reactive substances (TBARs), and particularly one of them, malondialdehyde (MDA), which are markers of lipid peroxidation (21); glutathione disulfide (GSSG), which is a marker of reduced glutathione (GSH) oxidation (22); and nitrotyrosine (NTT), which is a marker of peroxynitrite-induced oxidative/nitrosative stress (23).

To measure MDA, the standard method described by Londero and Lo Greco (24) was used. When MDA reacts with TBA, the MDA-TBA complex is separated from interfering substances and specifically identified using reverse-phase high-performance liquid chromatography coupled with $\mathrm{UV} /$ visible detection. MDA is quantified on the basis of its strong light-absorbing and fluorescing properties following the reaction with TBA. The results are expressed in $\mu \mathrm{M}$. For the dosage of lipid peroxidation intermediates, all plasma TBARs were measured, including MDA, using a method similar to that of Ohkawa et al (25). The present method was based on the reaction of the aldehyde function of TBARs released by acid hydrolysis at $95^{\circ} \mathrm{C}$ with TBA to form a TBAR-TBA colored complex, which is quantified by fluorometry. Results are expressed in $\mu \mathrm{M}$. Total glutathione (GluT), GSH and oxidized glutathione (GSSG) were determined enzymatically from the acidic protein-free supernatant, according to the method of Akerboom and Sies (26). The assay for GSSG was performed subsequent to masking GSH by adding 2-vinylpyridine to the deproteinized extract. The assay for NTT was performed according to the method of Ischiropoulos et al (27), which uses a competitive ELISA test (OxiSelect ${ }^{\mathrm{TM}}$ Nitrotyrosine ELISA kit; cat. no. STA-305; Cell Biolabs Inc., San Diego, CA, USA). For the determination of this last marker (NTT), plasma was first added to a nitrated bovine serum albumin (BSA) (OxiSelect ${ }^{\mathrm{TM}}$ Nitrotyrosine ELISA kit; cat. no. STA-319) preabsorbed enzyme immunoassay plate. 
Following a brief incubation, a specific anti-nitrotyrosine antibody (OxiSelect ${ }^{\mathrm{TM}}$ Nitrotyrosine ELISA kit; part no. 230502) was added, followed by the addition of a horseradish peroxidase (HRP)-conjugated secondary antibody [OxiSelect ${ }^{\mathrm{TM}}$ Nitrotyrosine ELISA kit; HRP Conjugate (part no. 231009)]. The dilution of the anti-nitrotyrosine antibody was 1:1,000 and that of the secondary antibody was 1:1,000, and the incubation was performed at room temperature for $1 \mathrm{~h}$. The protein NTT content in the plasmatic sample was determined by comparison with a standardized curve that was established from predetermined nitrated BSA standards, the results being expressed in $\mu \mathrm{g} / \mathrm{ml}$.

Antioxidative non-enzymatic proteins. For the non-enzymatic antioxidative response assessment, the total thiol group molecules, which comprise such peptides as glutathione and cysteine- and/or homocysteine-containing proteins, were measured in the plasma. For the dosage of the total SH group molecules, 5,5'-dithio-bis (2-nitrobenzoic acid) was used as reagent and the level of plasmatic $\mathrm{SH}$ group molecules was measured spectrophotometrically at $412 \mathrm{~nm}$. The results are expressed in U/1 (28). The dosage of GluT, GSH and GSSG in the plasma was calculated using the method of Akerboom and Sies (26). Prior to centrifugation (400 x g; $\left.10 \mathrm{~min} ; 4^{\circ} \mathrm{C}\right)$, $400 \mu \mathrm{l}$ whole blood was collected in $3.6 \mathrm{ml}$ metaphoric acid. Following centrifugation, GluT and GSH were measured enzymatically in the acidic protein-free-supernatant. The assay of GSSG was performed following masking of GSH by adding 2-vinylpyridine to the deproteinized extract. Similar to GluT and GSH, GSSG was measured enzymatically. Results are expressed in $\mu \mathrm{M}$.

Antioxidative enzymatic proteins. Measurement of the antioxidative enzymes was performed in RBCs only, or in $\mathrm{RBCs}$ and plasma. To measure $\mathrm{Cu}-\mathrm{Zn}$ superoxide dismutase (SOD1) activity in RBCs, the method described by Marklund and Marklund (29) was used, which consists of a simple and rapid test based on the ability of SOD1 to inhibit the autoxidation of pyrogallol. The principle of this method is based on the competition between pyrogallol autoxidation by the superoxide anion $\left(\mathrm{O}_{2}^{-}\right)$and the dismutation of this radical by SOD1. In this method, the rate of pyrogallol autooxidation was determined spectrophotometrically from the increase in absorbance at $420 \mathrm{~nm}$; 1 unit of SOD1 activity was defined as the amount of the enzyme required to inhibit the rate of pyrogallol autooxidation by $50 \%$. Results are expressed in $\mathrm{U} / \mathrm{mg}$ hemoglobin $(\mathrm{Hb})$. For the dosage of glutathione reductase (GR), a standard Randox kit-based colorimetric method was used (cat. no. GR2368; Randox Laboratories, Crumlin, $\mathrm{UK})$. Results are expressed in U/g Hb for GR in RBCs, and $\mathrm{U} / \mathrm{l}$ for GR in plasma (30). In addition, glutathione peroxidase (GPx) activity was measured in RBCs and plasma, according to a method derived from that of Günzler et al (31). The GPX assay was based on the oxidation of reduced nicotinamide dinucleotide phosphate (NADPH) to $\mathrm{NADP}^{+}$, which is associated with a decrease in the absorbance at $340 \mathrm{~nm}$. The rate of this decrease is directly proportional to the GPx activity in the sample. GPx activity was subsequently evaluated in $\mathrm{nM}$ NADPH oxidized/min, and the results are expressed in $\mathrm{U} / \mathrm{g} \mathrm{Hb}$ for GPx in RBCs and in U/l for GPx in plasma.
Statistical analysis. A total of two different statistical tests were used: i) The two-tailed Student's t-test, for comparison between patient values and normal control reference values; and ii) Pearson's correlation test for analyzing the statistical association between the different variables of interest, including oxidative and antioxidative stress-associated biomarkers. All statistical analysis was performed using the XLSTAT software (XLSTAT 2018.1.49725; Addinsoft; https://www.xlstat. com). Considering the fact that the two-tailed Student's t-test was used to perform three comparisons (total EHS patients values, EHS patients with values above upper normal limits and EHS patients with values below the lower normal limits) with the one dataset of normal control reference values, the Bonferroni correction was applied, which sets the $\alpha$ cut-off of significance at $0.05 / 3$, i.e. 0.016 . While statistical analysis using the Pearson's correlation test was done with the cut-off value of $\alpha=0.05$.

\section{Results}

Demographic data. A total of 32 EMFIS-bearing patients were included in this prospective study for oxidative and antioxidative stress biomarker analysis. The mean age was 50.6 years, ranging between 32 and 75 years. There were 22 females and 10 males, for an overall female/male sex ratio of $69 \%$.

However, since NTT was measured in only 14 of the 32 cases in this series, the results obtained from a concomitant series of 46 additional EHS self-reporting patients (mean age, 49 years; female/male sex ratio, $71 \%$ female), all complying with the inclusion criteria (see above), were added, thus the results presented for NTT are based on the analysis of an overall number of 60 EMFIS-bearing patients. The demographic data are presented in Table III.

Oxidative stress biomarkers. The results are depicted in Fig. 1, and in Tables IV and V. Fig. 1 presents the distribution values of the different oxidative stress biomarkers analyzed in EMFIS-bearing patients in comparison with normal-range values obtained from healthy controls. As indicated in Fig. 1, for a number of cases, TBARs, MDA, GSSG and NTT peripheral blood level values were above the upper normal limits, meaning that these cases were associated with detectable oxidative stress in the peripheral blood. These data are confirmed in Table IV. Overall, in comparison with normal-range values, the mean values ( \pm standard deviation) for all 32 patients analyzed were statistically significantly increased for TBARs $(\mathrm{P}=0.013)$, and tended to be increased for MDA and GSSG ( $\mathrm{P}=0.053$ and $\mathrm{P}=0.051$ respectively), although not for NTT $(\mathrm{P}=0.790)$. However, when restricting the analysis to EMFIS-bearing patients having values above the upper normal limits, relative to the values obtained in normal healthy controls (this concerns $30-50 \%$ of the patients, depending on the biomarker considered), a statistically significant difference was evident for TBARs, in addition to MDA, GSSG and NTT $(\mathrm{P}<0.0001)$; that is, for all the oxidative stress biomarkers analyzed thus far.

Non-enzymatic protein-associated biomarkers. By contrast, as indicated in Fig. 1, considering the overall series of patients investigated, all values for the total protein thiol 
Table II. Methods of measurement of oxidative stress-associated biomarkers, antioxidative non-enzymatic proteins and antioxidative enzymes in the plasma and/or red blood cells in electrohypersensitivity self-reporting patients, with electromagnetic field intolerance syndrome.

\begin{tabular}{|c|c|c|c|}
\hline Author, year & $\begin{array}{c}\text { Biomarkers } \\
\text { oxidative stress }\end{array}$ & Sample type & (Refs.) \\
\hline Londero and Lo Greco, 1996 & MDA & Plasma & (24) \\
\hline Okhawa et al, 1979 & TBARS & Plasma & $(25)$ \\
\hline Akerboom and Sies, 1981 & GSSG & Plasma & (26) \\
\hline Ischiropoulos et al, 1992 & $\begin{array}{l}\text { NTT } \\
\text { Antioxidative non-enzymatic proteins }\end{array}$ & Plasma & $(27)$ \\
\hline Jocelyn, 1987 & Total thiol & Plasma & (28) \\
\hline Akerboom and Sies, 1981 & GSH & Plasma & (26) \\
\hline Akerboom and Sies, 1981 & $\begin{array}{l}\text { GluTa } \\
\text { Antioxidative enzymes }\end{array}$ & Plasma & (26) \\
\hline Marklund and Marklund, 1974 & SOD & $\mathrm{RBC}$ & (29) \\
\hline Mannervik, 2001 & GR & Plasma/RBC & (30) \\
\hline Günzler et al, 1974 & GPx & Plasma/RBC & $(31)$ \\
\hline
\end{tabular}

Table III. Demographic data.

\begin{tabular}{lccc}
\hline $\begin{array}{l}\text { No. } \\
\text { cases }\end{array}$ & $\begin{array}{c}\text { Mean } \\
\text { age, years }\end{array}$ & $\begin{array}{c}\text { Age } \\
\text { range, years }\end{array}$ & $\begin{array}{c}\text { Sex ratio, } \\
\text { F/M }(\% \mathrm{~F})\end{array}$ \\
\hline $32^{\mathrm{a}}$ & 50.6 & $32-75$ & $22 / 10(69)$ \\
$46^{\mathrm{b}}$ & 49 & $19-79$ & $33 / 13(71)$ \\
$123^{\mathrm{c}}$ & 44 & $18-65$ & $61 / 62(50)$ \\
\hline
\end{tabular}

${ }^{a}$ Measurement of all markers in 32 EHS self-reporting patients except for NTT which was measured in 14 patients. ${ }^{\mathrm{b}}$ Measurement of NTT in 46 additional patients from a concomitant series of EHS self-reporting patients. NTT, nitrotyrosine; EHS, electrohypersensitivity. ${ }^{\text {T These }}$ historical apparently-normal controls were selected on the basis of a lack of clinical symptoms and medical history of diseases.

group were within the limits of normal-range values. There were also no blood level values above the upper normal limits for GSH, the GSH/GSSG ratio, GluT and the GSH/GluT ratio; however, in a number of cases, for these GSH-related biomarkers and for NTT, blood level values were below the normal-range values. These data are detailed in Table V. When analyzing the overall series of patients, all investigated biomarkers, with the exception of GluT and NTT, were observed to be statistically significantly below the lower normal limit values. However, when considering the $20-40 \%$ of patients with values below the lower normal limit values, this finding was confirmed for these biomarkers and also for GluT and NTT $(\mathrm{P}<0.0001)$, suggesting that certain oxidative stress-associated biomolecular processes resulting in a decrease in GSH, GluT and NTT may have occurred in these particular cases.

Antioxidative stress enzymes. The previous oxidative stress data were confirmed by measuring a number of antioxidative stress-associated key enzymes in RBCs and plasma. The results are depicted in Fig. 2 and Table VI. An important observation indicated in Fig. 2 was that SOD1 activity measured in RBCs was associated with values above the upper normal limits in $\sim 60 \%$ of the patients, suggesting that this antioxidative stress-inducible enzyme is primarily involved in the oxidative stress detoxification process occurring in EMFIS-bearing patients. Furthermore Table VI indicates that when considering all included cases, there was statistically significantly increased activity in RBCs of SOD1, although not GPx $(\mathrm{P}=0.002$ and $\mathrm{P}=0.044$, respectively), and of GPx in the plasma. Likewise, in comparison with normal-range values, the mean values ( \pm standard deviation) obtained in the $\sim 60 \%$ of EMFIS-bearing patients having increased SOD1 activity, were revealed to be statistically significantly increased $(\mathrm{P}<0.0001)$. However, when restricting the analysis to the patients with GPx and CG increases, as indicated in Table VI, a statistically significant difference in comparison with normal control reference values in RBCs and plasma was identified in 19 and $10 \%$ of the patients respectively, and for GR in RBCs in $\sim 6 \%$ $(\mathrm{P}<0.0001)$, meaning that EMFIS may be characterized by increased antioxidative stress-associated enzymatic activity in RBCs, primarily involving SOD1.

Overall oxidative stress occurrence in EMFIS-bearing patients. Table VII reports the overall results obtained with the 

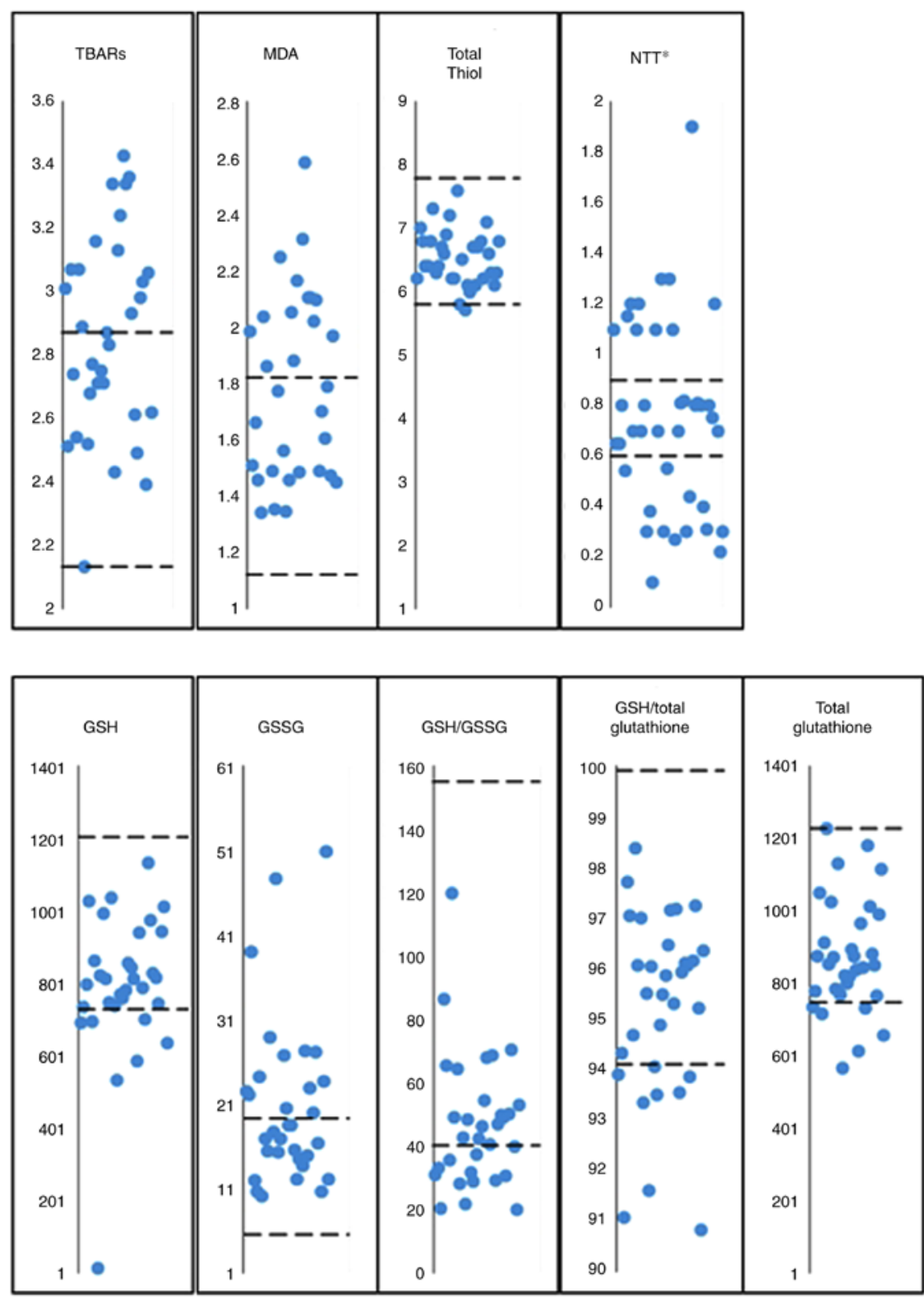

Figure 1. Values of oxidative stress biomarkers in the plasma of EHS self-reporting patients (electromagnetic fields intolerance syndrome-bearing patients) in comparison with normal range values. "Data were obtained from an overall series of 60 EHS self-reporting patients. TBARs, thiobarbituric acid-reactive substances; MDA, malondialdehyde; NTT, nitrotyrosine; GSH, reduced glutathione; GSSG, oxidized glutathione; EHS, electrohypersensitivity.

three principal categories of oxidative stress biomarkers used in this study: TBARs/MDA, GSSG and NTT. Fig. 3 summarizes the results: $42.85 \%$ of EHS self-reporting patients had one positive detectable oxidative stress biomarker, and 21.43 and $14.28 \%$ had 2 or 3 positive detectable oxidative stress biomarkers, respectively, meaning that overall, $80-90 \%$ of the cases were associated with at least one detectable oxidative stress biomarker in the peripheral blood. However, in order to provide a comprehensive interpretation of the findings characterizing EMFIS, the present study included a provisional molecular bioanalysis of the different results obtained, as presented in Figs. 4-6.

Search for statistical correlations. Using Pearson's statistical correlation test, the present study sought to identify a correlation between the different biological parameters so far investigated.
Table VIII reports the results. It was observed that the plasma level of MDA (a well-known TBAR) was positively correlated with the TBAR plasma level, and that the GSSG plasma level was positively correlated with GSH and GluT plasma levels, and with GSH/GluT and GSH/GSSG ratios.

Furthermore, it was observed that the GSH/GSSG ratio was positively correlated with SOD1 activity in RBC, as tended to be the case for the GSH/GluT ratio $(\mathrm{P}=0.06)$. It was additionally identified that the GSH plasma level was positively correlated with the GPx activity level in plasma, although not with GPx activity in $\mathrm{RBCs}(\mathrm{P}=0.371)$.

\section{Discussion}

It is well established that oxidative stress may cause profound alterations in biomolecules, including lipids, proteins and nucleic acids, and consequently may alter various cellular 
Table IV. Electromagnetic field intolerance syndrome-associated oxidative stress biomarkers measured in the peripheral blood of EHS self-reporting patients, including mean values $( \pm$ SD) for all patients, and mean values $( \pm$ SD), numbers and percentages of patients with mean values above the upper normal limits.

\begin{tabular}{|c|c|c|c|c|c|c|c|}
\hline \multirow[b]{2}{*}{$\begin{array}{l}\text { Oxidative stress } \\
\text { biomarkers }\end{array}$} & \multirow[b]{2}{*}{ Normal values (range) } & \multirow[b]{2}{*}{$\begin{array}{l}\text { Patients with EHS } \\
\text { Mean } \pm \text { SD }\end{array}$} & \multirow[b]{2}{*}{ P-value } & \multicolumn{3}{|c|}{$\begin{array}{l}\text { Patients with EHS with values } \\
\text { above upper normal limits }\end{array}$} & \multirow[b]{2}{*}{ P-value ${ }^{b}$} \\
\hline & & & & $\begin{array}{l}\text { No. of } \\
\text { cases }\end{array}$ & $\begin{array}{l}\% \text { of } \\
\text { total cases }\end{array}$ & Mean \pm SD & \\
\hline TBARS & $2.5 \pm 0.18(2.13-2.86) \mu \mathrm{M}$ & $2.85 \pm 0.06$ & 0.013 & $15 / 32$ & 48.88 & $3.14 \pm 0.17$ & $<0.0001$ \\
\hline MDA & $1.46 \pm 0.17(1.12-1.81) \mu \mathrm{M}$ & $1.76 \pm 0.06$ & 0.053 & $14 / 32$ & 43.75 & $2.10 \pm 0.19$ & $<0.0001$ \\
\hline GSSG & $12.4 \pm 3.4(5.5-19.3) \mu \mathrm{M}$ & $20.74 \pm 1.74$ & 0.051 & $13 / 32$ & 40.63 & $29.46 \pm 9.95$ & $<0.0001$ \\
\hline NTT & $0.75 \pm 0.08(0.6-0.9) \mu \mathrm{g} / \mathrm{ml}$ & $0.78 \pm 0.35$ & 0.790 & $20 / 60$ & 33.33 & $1.19 \pm 0.21$ & $<0.0001$ \\
\hline
\end{tabular}

Table V. Electromagnetic field intolerance syndrome-associated non-enzymatic protein biomarkers measured in the peripheral blood of EHS self-reporting patients, including mean values $( \pm \mathrm{SD})$ for all patients, and mean values $( \pm \mathrm{SD})$, numbers and percentages of patients with mean values above the upper normal limits.

Patients with EHS with values above upper normal limits

\begin{tabular}{|c|c|c|c|c|c|c|c|}
\hline \multirow[b]{2}{*}{$\begin{array}{l}\text { Oxidative } \\
\text { stress biomarkers }\end{array}$} & \multirow[b]{2}{*}{$\begin{array}{c}\text { Normal } \\
\text { values (range) }\end{array}$} & \multirow[b]{2}{*}{$\begin{array}{c}\text { Patients with EHS } \\
\text { Mean } \pm \text { SD }\end{array}$} & \multirow[b]{2}{*}{ P-value ${ }^{a}$} & & & & \multirow[b]{2}{*}{ P-value } \\
\hline & & & & $\begin{array}{l}\text { No. of } \\
\text { cases }\end{array}$ & $\begin{array}{c}\% \text { of } \\
\text { total cases }\end{array}$ & Mean & \\
\hline 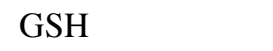 & 9 & & & & & .27 & \\
\hline GSH/GSSG ratio & $84.15 \pm 29.35$ & 46 & $<0.0001$ & $13 / 32$ & 40.63 & 29. & $<0.0001$ \\
\hline GluT & $989 \pm 120(749-1228) \mu \mathrm{M}$ & $873.47 \pm 27.85$ & 0.041 & $6 / 32$ & 18.75 & 669.8 & $<0.0001$ \\
\hline GSH/GluT ratio & $99 \pm 0.19(94.1-99.9) \%$ & $95.25 \pm 0.33$ & 0.0009 & $9 / 32$ & 29.13 & $92.86 \pm 1.29$ & $<0.0001$ \\
\hline NTT & $0.75 \pm 0.08(0.6-0.9) \mu \mathrm{g} / \mathrm{ml}$ & $0.78 \pm 0.35$ & 0.790 & $20 / 60$ & 33.33 & $0.41 \pm 0.14$ & $<0.0001$ \\
\hline
\end{tabular}

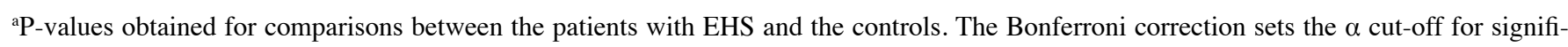
cance at $0.016 .{ }^{b} \mathrm{P}$-values obtained for comparison between the patients with EHS with values above the upper normal limits and the control group. The Bonferroni correction sets the $\alpha$ cut-off for significance at 0.016 . NTT, nitrotyrosine; GSSG, oxidized glutathione; GSH, reduced glutathione; GluT, total glutathione; EHS, electrohypersensitivity; SD, standard deviation.

functions and structures $(32,33)$. This explains why oxidative stress has been implicated in ageing and in a number of age-associated pathologies, including cancer, Alzheimer's disease, diabetes and cardiovascular diseases through genetic and/or epigenetic mechanisms (34). Concerning more particularly the role of oxidative stress in tumorigenesis, a general free radical theory was recently proposed linking oxidative stress to direct genetic toxicity and DNA mutagenesis, and indirectly to epigenetic alterations through free radical-induced protein epimutations (35). The present study reports for the first time, to the best of our knowledge, that $\sim 80 \%$ of so-called EHS self-reporting patients present with oxidative stress, and thus may be considered to be bearing a truly objective pathological disorder, as is the case for cancer, Alzheimer's disease, or other diseases or pathological conditions. In the present study, the term EMFIS was preferred to EHS since, according to the clinical criteria used, it was not possible to clearly assess whether the patients exhibited a decreased tolerance threshold when exposed to EMFs. Furthermore, the term EMFIS was used preferentially to IEI-EMF, which has been proposed by the WHO, as all patients included in the present study clearly reported EMF-associated clinical symptoms (4).

During oxidative stress, among the reactive oxygen species (ROS) are the superoxide anion $\left(\mathrm{O}_{2}{ }^{\circ}\right)$, hydrogen peroxide $\left(\mathrm{H}_{2} \mathrm{O}_{2}\right)$, the hydroxyl radical $\left(\mathrm{OH}^{\circ}\right)$ and the hydroperoxyl radical $\left(\mathrm{O}_{2} \mathrm{H}^{\circ}\right)$. Further, in redox cycling, transition metals including $\mathrm{Fe}, \mathrm{Cu}, \mathrm{Ni}$ and $\mathrm{Co}$ serve an important role in ROS formation (36).

$\mathrm{Fe}$ is the most commonly involved transition metal, and there are three classical reaction types. In the first step, namely the Haber-Weiss reaction, the superoxide anion reduces ferric ion into ferrous ion: $\mathrm{Fe}^{3+}+\mathrm{O}_{2}{ }^{\circ-} \rightarrow \mathrm{Fe}^{2+}+\mathrm{O}_{2}[\mathrm{~A}]$; while in a second step, namely the Fenton reaction, ferrous ion reacts 


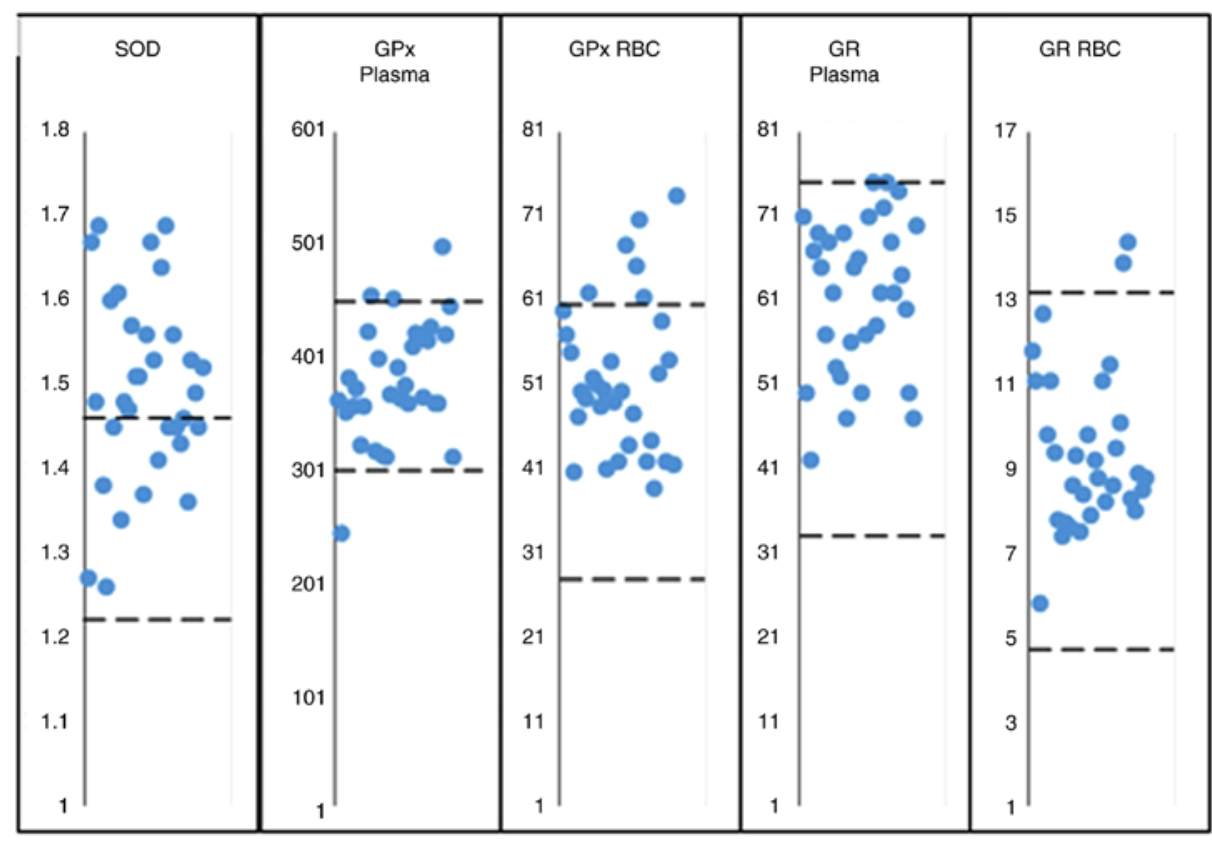

Figure 2. Values of specific activity of antioxidative detoxification enzymes measured in the plasma and RBCs of electrohypersensitivity self-reporting patients (electromagnetic fields intolerance syndrome-bearing patients) in comparison with normal range values. For GPx and GR, the patients with elevated plasma levels were different from those with elevated RBC levels. SOD, superoxide dismutase; GPx, glutathione peroxidase; GR, glutathione reductase; RBC, red blood cell.

with hydrogen peroxide to generate hydroxyl radicals and hydroxide ions: $\mathrm{Fe}^{2+}+\mathrm{H}_{2} \mathrm{O}_{2} \rightarrow \mathrm{Fe}^{3+}+\mathrm{OH}^{\circ}+\mathrm{OH}^{-}[\mathrm{B}]$.

Finally, in a third reaction, ferric ion is reduced to ferrous ion by reacting with a second hydrogen peroxide molecule, to recycle ferrous ion and form a hydroperoxyl radical and a proton: $\mathrm{Fe}^{3+}+\mathrm{H}_{2} \mathrm{O}_{2} \rightarrow \mathrm{Fe}^{2+}+\mathrm{O}_{2} \mathrm{H}^{\circ}+\mathrm{H}^{+}[\mathrm{C}]$.

The net effect of [B] and [C] is the generation of the two ROS, $\mathrm{OH}^{\circ}$ and $\mathrm{O}_{2} \mathrm{H}^{\circ}$, with $\mathrm{H}_{2} \mathrm{O}$ as a byproduct.

ROS are, however, difficult to measure directly due to their very short half-life. This explains why measurement of the products resulting from the molecular damage induced by ROS is the usual way to assess and measure oxidative stress. To that end, different oxidative stress and antioxidative response biomarkers were selected in the present study, representative of the different biochemical pathways and biological structural alterations that may occur when the organism is subjected to environmental stressors (37).

TBARs, which reflect the overall damage induced by non-enzymatic ROS-associated lipid peroxidation, among which MDA is the most prevalent byproduct (38), are commonly used biomarkers of lipoxidative stress (21). The reactive aldehyde MDA is a major indicator of the tissue damage resulting from the peroxidation of polyunsaturated fatty acids (PUFAs) induced by the two most prevalent ROS involved in lipoxidative stress: $\mathrm{OH}^{\circ}$ and $\mathrm{O}_{2} \mathrm{H}^{\circ}(39)$.

In fact, lipid peroxidation leads to the formation of numerous aldehydes, among which certain of them are highly reactive and may be considered as secondary messengers, which disseminate and amplify the initial oxidative stress. This is particularly the case for MDA, which is a bi-functional electrophile that is able to react strongly with nucleophiles, including amino acid residues in proteins (39). MDA adducts are thus biologically highly toxic, since they induce profound alterations in the structure and function of biomolecules by creating intramolecular or intermolecular protein/DNA cross-links $(40,41)$.

This may explain why the majority of assays that have been developed to measure MDA on the basis of its derivatization with TBA have been challenged for their relative lack of specificity (42). This is due to the fact that TBA (in addition to MDA) is able to react spontaneously with numerous other molecules present in the test tube; by using a high temperature (90-100 $\left.{ }^{\circ} \mathrm{C}\right)$ to obtain the TBA/MDA spectrophotometrically-measurable condensation product, the process is able to generate in vitro further oxidation (43). In the present study, the method developed by Londero and Lo Greco (24) was used, which is considered to minimize the biases due to the procedure itself, and thus may increase specificity. Moreover, TBARs and MDA were measured simultaneously in the same sample and the values obtained for these two biomarkers were compared with the normal-range values obtained in healthy controls. Using this procedure, it was demonstrated that $40-50 \%$ of the patients had statistically significantly increased TBAR and MDA mean plasmatic values relative to normal values, a finding which strongly suggests that these patients present with an increased lipid peroxidation state detectable in their peripheral blood. In addition, these data were confirmed in the overall sample of 32 patients studied for TBARs, and tended to be significant for MDA.

Indeed these data may not be restricted to the peripheral blood, since cellular and nuclear membranes are primarily composed of fatty acids, including PUFAs. In the past 20 years MDA has been recognized as a reliable lipid peroxidation marker in a number of diseases, including cancer (44-47), type 2 diabetes (48), cardiovascular diseases $(49,50)$ and Alzheimer's disease (51). On the basis of the present data, this is also the case for EMFIS, and this result is unsurprising since oxidative stress, including lipid peroxidation, has also been evidenced in 
Table VI. Electromagnetic field intolerance syndrome-associated antioxidative detoxification enzymatic activity measured in red blood cells and the plasma of EHS self-reporting patients, including mean values $( \pm$ SD) for all patients, and mean values $( \pm$ SD), number and percentage of patients with mean values above the upper normal limits.

\begin{tabular}{|c|c|c|c|c|c|c|c|}
\hline \multirow[b]{2}{*}{$\begin{array}{l}\text { Anti-oxidative } \\
\text { stress enzymes }\end{array}$} & \multirow[b]{2}{*}{ Normal values (range) } & \multirow[b]{2}{*}{$\begin{array}{l}\text { Patients with EHS } \\
\text { Mean } \pm \text { SD }\end{array}$} & \multirow[b]{2}{*}{ P-value ${ }^{a}$} & \multicolumn{3}{|c|}{$\begin{array}{l}\text { Patients with EHS with values } \\
\text { above upper normal limits }\end{array}$} & \multirow[b]{2}{*}{ P-value } \\
\hline & & & & $\begin{array}{l}\text { No. of } \\
\text { cases }\end{array}$ & $\begin{array}{c}\% \text { of } \\
\text { total cases }\end{array}$ & Mean \pm SD & \\
\hline SOD (RBC) & $1.34 \pm 0.06(1.22-1.46) \mathrm{U} / \mathrm{mg} \mathrm{Hb}$ & $1.50 \pm 0.02$ & 0.002 & $19 / 32$ & 59.38 & $1.57 \pm 0.08$ & $<0.0001$ \\
\hline GPx (RBC) & $44.1 \pm 8.2(27.8-60.5) \mathrm{U} / \mathrm{g} \mathrm{Hb}$ & $51.92 \pm 1.62$ & 0.044 & $6 / 32$ & 18.75 & $66.70 \pm 4.76$ & $<0.0001$ \\
\hline GPx (plasma) & $375 \pm 37.5(300-450) \mathrm{U} / 1$ & $379.28 \pm 9.30$ & 0.83 & $3 / 32$ & 9.38 & $469.67 \pm 26.31$ & $<0.0001$ \\
\hline GR (RBC) & $8.9 \pm 2.1(4.7-13.2) \mathrm{U} / \mathrm{g} \mathrm{Hb}$ & $9.42 \pm 0.34$ & 0.56 & $2 / 32$ & 6.25 & $14.15 \pm 0.35$ & $<0.0001$ \\
\hline GR (plasma) & $54 \pm 9(33-75) \mathrm{U} / 1$ & $61.69 \pm 9.17$ & 0.16 & 0 & 0 & - & - \\
\hline
\end{tabular}

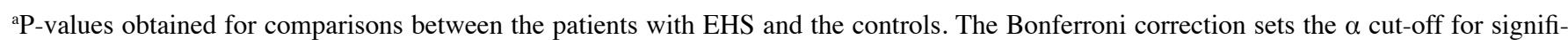
cance at 0.016 . ${ }^{\mathrm{b}} \mathrm{P}$-values obtained for comparison between the patients with EHS with values above the upper normal limits and the control group. The Bonferroni correction sets the $\alpha$ cut-off for significance at 0.016 . SOD, superoxide dismutase; GR, glutathione reductase; GPx, glutathione peroxidase; RBC, red blood cell.

Table VII. Percentage of electrohypersensitivity self-reporting patients (electromagnetic field intolerance syndrome-bearing patients) having positive TBARs, GSSG and/or NTT oxidative stress biomarkers measured in the peripheral blood.

\begin{tabular}{llc}
$\begin{array}{l}\text { No. of positive } \\
\text { biomarkers }\end{array}$ & \multicolumn{1}{c}{ Markers } & $\begin{array}{c}\text { Percentage of } \\
\text { patients (\%) }\end{array}$ \\
\hline 1 & NTT & 14.28 \\
& GSSG & 7.14 \\
& TBARs & 21.43 \\
& NTT or GSSG or TBARs & 42.85 \\
2 & TBARs and GSSG & 7.14 \\
& NTT and TBARs & 7.14 \\
& NTT and GSSG & 7.14 \\
& TBARs and GSSG, or & 21.42 \\
& NTT and TBARs, or NTT & \\
& and GSSG & \\
& NTT and TBARs and GSSG & 14.28 \\
\hline
\end{tabular}

TBARs, thiobarbituric acid reactive substances; NTT, nitrotyrosine; GSSG, oxidized glutathione.

similar recognized pathological conditions, including chronic fatigue syndrome (CFS) (52-56) and MCS (57).

However, as previously outlined, oxidative stress is an extremely complex redox cycling process resulting in various oxidizing/nitrosating free radical and molecular species attacks that exceed natural defense mechanisms; thus, it may not be measured by only one biomarker. In addition to TBARs and MDA, the present study measured GSH and, more specifically, GSSG and NTT as oxidative stress biomarkers. Glutathione is the primary compound that determines the redox state of a cell. It is a prototype antioxidant involved in cellular protection from the noxious effects of oxidative stress, directly and as cofactor of GPx. This thiol-containing tripeptide exists in an oxidized (GSSG) and reduced (GSH) form, and thus is a nucleophile and a reducing agent that is able to react with electrophilic and oxidizing species, allowing cells to escape the interaction of ROS with critical molecular targets, including proteins or nucleic acids (58). The ratio of GSH to the GSSG is a well-known marker of the redox state of a cell (59). Consequently GSH and GSSG were measured and their ratio (GSH/GSSG) and sum (GluT) were determined for the analysis of oxidative stress and the antioxidative stress response.

During oxidative stress, GSSG results from the oxidation of two GSH molecules by one hydrogen peroxide molecule, according to the following formula: $2 \mathrm{GSH}+\mathrm{H}_{2} \mathrm{O}_{2} \mathrm{GSSG}+$ $2 \mathrm{H}_{2} \mathrm{O}$ [D]; while the two GSH molecules are usually recycled from the reduction of GSSG, according to a reaction involving the coenzyme NADPH: GSSG + NADPH $2 \mathrm{GSH}+\mathrm{NADP}^{+}[\mathrm{E}]$.

It is notable that the oxidation of GSH according to [D] is catalyzed by GPx, while the reduction of GSSG according to [E] is catalyzed by GR; thus, according to [D] and [E], the activity of these two key enzymes in RBCs and plasma was measured.

In the present study, it was demonstrated that in comparison with normal-range values, the GSSG plasmatic mean value was statistically significantly increased in $40 \%$ of the patients, meaning that these patients presented with an oxidative redox state detectable in their peripheral blood. However, these data were not confirmed for the overall 32-patient sample for which the mean GSSG plasmatic mean value was not statistically significantly increased.

According to [D], it is assumed that increased GSSG may result in GSH depletion and consequently contribute to a decrease in antioxidant defenses. This may explain the result that in the overall patient sample studied, mean plasmatic values of GSH, the GSH/GSSG ratio and the GSH/GluT ratio were all statistically significantly decreased in comparison with normal control values; and that $20-40 \%$ of the patients 


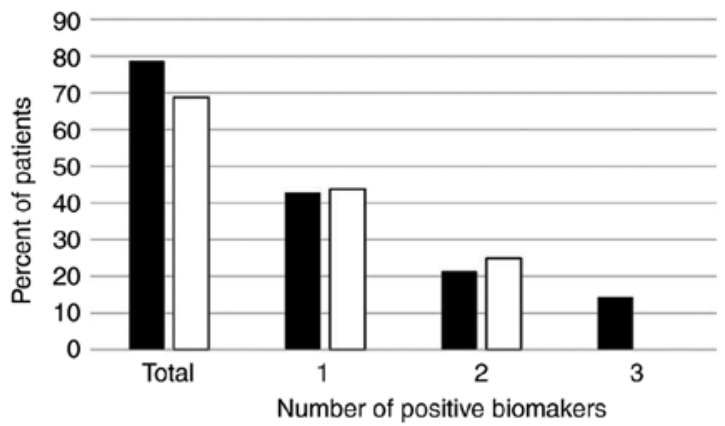

Figure 3. Percentage of electrohypersensitivity self-reporting patients (electromagnetic fields intolerance syndrome-bearing patients) having positive TBARs, GSSG and/or NTT oxidative stress biomarkers measured in the peripheral blood. Positive biomarkers correspond to marker levels above the upper normal limit; 'total' corresponds to the patients with one or more positive biomarkers. Black bars indicate the percentage of patients with one, two or three of the three positive biomarkers (TBARS, GSSG and NTT), detected in 14 of the 32 included patients; white bars indicate the percentage of patients with one or two out of TBARs and GSSG in the total 32 included patients. TBARs, thiobarbituric acid-reactive substances; GSSG, oxidized glutathione; NTT, nitrotyrosine.

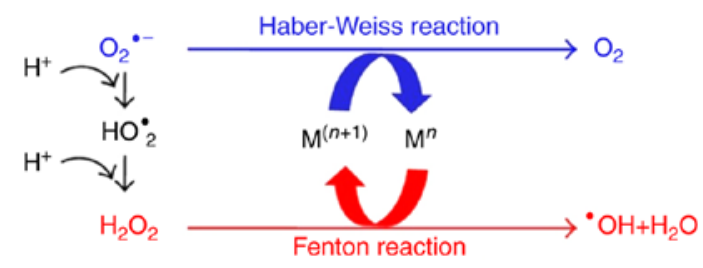

Figure 4. Fenton and Haber-Weiss reactions. Reduced form of transition-metals $(\mathrm{M} \mathrm{n})$ is oxidized by hydrogen peroxide to oxidized form of transition metals $[\mathrm{M}(\mathrm{n}+1)]$, forming hydroxyl radical and water as byproducts. Superoxide radical $\left(\mathrm{O}_{2}{ }^{-}\right)$can also react with oxidized form of transition metals $[M(n+1)]$ in the Haber-Weiss reaction leading to the production of reduced form of transition-metals $(\mathrm{M} \mathrm{n})$.

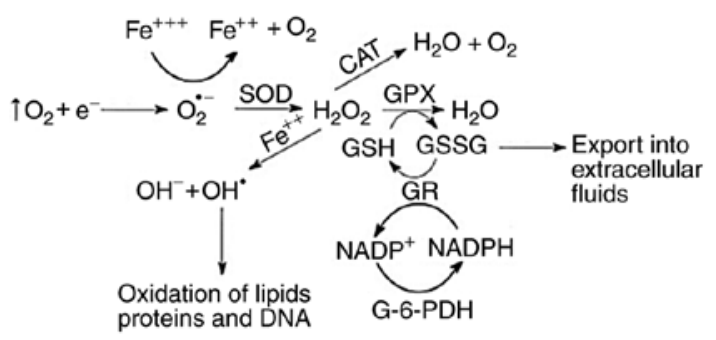

Figure 5. Schematic diagram showing the detoxification role of GSH, SOD1, GPx, GR and Cat during oxidative stress. Superoxide radical can be generated through the activation of specialized enzymes or be generated as by-product of abnormal cellular metabolism, occurring particularly from the mitochondrial electron transport chain. Superoxide dismutase then converts superoxide to hydrogen peroxide which has to be rapidly removed from the system. This is generally achieved by catalases or peroxidases, such as the glutathione peroxidases which use reduced glutathione (GSH) as electron donor. Alternatively Iron(II) (present in the system) is oxidized by hydrogen peroxide to iron(III), forming hydroxyl radical and hydroxide ion. GSH, reduced glutathione; SOD1, Cu-Zn superoxide dismutase; GPx, glutathione peroxidase; GR, glutathione reductase; Cat, catalase; NADPH, reduced nicotinamide adenine dinucleotide phosphate.

with values of these biomarkers below the lower normal limits presented with statistically significantly decreased mean values in comparison with normal values, a finding which

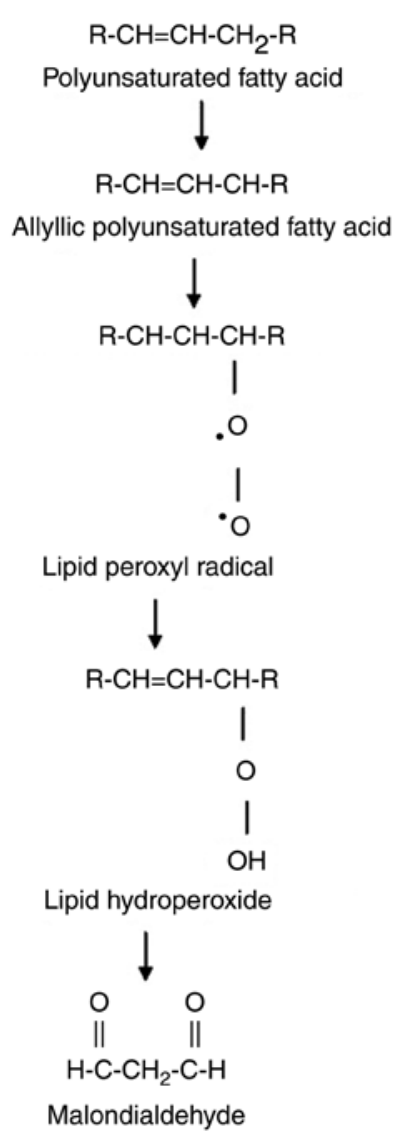

Figure 6. Schematic representation of the lipid peroxidative chain reaction leading to malondialdehyde. Malondialdehyde may be generated in vivo as a side product of PUFA decomposition by enzymatic processes during the biosynthesis of allylic PUFA, lipid peroxyl radical and lipid hydroperoxyde. PUFA, polyunsaturated fatty acid.

also confirmed that EHS self-reporting patients present with oxidative stress. Similar data were obtained in RBCs for GSH, although not for the GSSG/GluT ratio, in the De Luca et al (57) study, suggesting that the plasmatic measurement of GSSG, the GSH/GSSG ratio or the GSH/GluT ratio may be more informative compared with the measurement of the GSSG/GluT ratio in RBCs for the assessment of oxidative stress in EHS self-reporting patients.

Since the GSSG increase may be caused by an increase in GPx activity and/or by a decrease in GR activity, as indicated above, the present study measured the activity of these two key enzymes in RBCs and plasma. The overall mean GPx activity in the all 32 cases studied was not statistically significantly increased in RBCs and in plasma; with the exception of two cases, mean GR activity in RBCs and plasma was normal in all sample cases studied. However when considering the 18.75 and $9.28 \%$ of patients with increased GPx activity in RBCs and in plasma, respectively, a statistically significant difference was identified. Accordingly, it was suggested that the GSSG mean level increase in the peripheral blood may be associated with the increased GPx activity in $~ 19 \%$ of the patients, and/or by lower or normal GR activity; according to [E], the activity of this latter inducible enzyme is insufficient to recycle GSH from GSSG.

In the redox process GPx is an important enzyme as, by acting as a peroxynitrite reductase, it is able to efficiently 


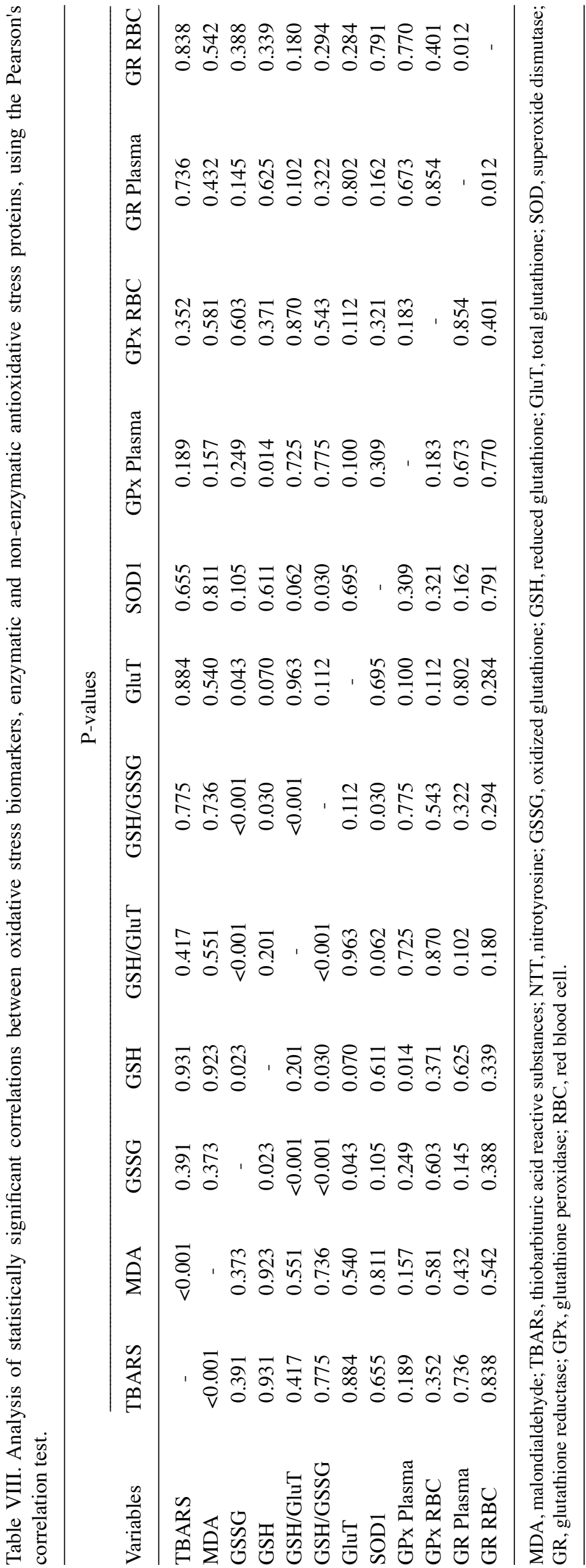


reduce peroxynitrite/peroxynitrous acid $\left(\mathrm{ONOO}^{-} / \mathrm{ONOOH}\right)$ into nitrite $(\mathrm{NO})$, thereby protecting cells against oxidative and nitrative reactions (60). The present data was not completely concordant with that obtained in the De Luca et al (57) study, which exhibited an overall statistically significant increase in GPx activity in RBCs in comparison with normal values. In addition, since GR activity was not measured in this latter study, it is not possible to confirm the accuracy of the present data demonstrating a normal level of GR activity in RBCs and plasma. In the present study, the evidence of oxidative stress in EHS self-reporting patients was, however, considerably reinforced by the evidence that, relative to normal values, the SOD1 mean value in RBCs was observed to be statistically significantly increased when considering the overall patient sample and the near $60 \%$ of the patients with mean values above the upper normal limit.

Such results were confirmed in patients with MCS in the De Luca et al (57) study, although not in patients with EHS; however, in these patients there was a strong tendency towards an increase in the SOD1 mean value in RBCs. The reason for such differences in comparison with the present data are not clear, and may be due to different inclusion criteria, since these criteria were not clearly detailed in the De Luca et al study, and/or to the use of a different dosage techniques.

SOD1 catalyzes the detoxification of the superoxide anion by dismuting this anion into hydrogen peroxide and molecular oxygen. $\mathrm{O}_{2}{ }^{\circ}+\mathrm{O}_{2}{ }^{\circ-}+2 \mathrm{H}^{+} \rightarrow \mathrm{H}_{2} \mathrm{O}_{2}+\mathrm{O}_{2}[\mathrm{~F}]$.

A further consideration to be made concerning the increased SOD1 activity in EMFIS-bearing patients is that according to [B] and [C], excessive production of $\mathrm{H}_{2} \mathrm{O}_{2}$ may provide excessive $\mathrm{OH}^{\circ}$ and $\mathrm{O}_{2} \mathrm{H}^{\circ}$ free radical and $\mathrm{OH}^{-}$ion production, and thus may amplify oxidative stress-induced detrimental health effects. Such a hypothesis is plausible since, in the present study, GPx activity was observed to be increased in only $10-18 \%$ of cases, thereby limiting its $\mathrm{H}_{2} \mathrm{O}_{2}$ detoxifying capacity. Another possibility for detoxifying $\mathrm{H}_{2} \mathrm{O}_{2}$ is catalase. However, catalase activity was not measured in the present study, although it was reported that in comparison with normal controls catalase activity tends to be decreased in EHS self-reporting patients (57), meaning that the $\mathrm{H}_{2} \mathrm{O}_{2}$ detoxifying capacity of catalase may be not sufficient in these patients.

It is possible, according to [D] and [F] by providing $\mathrm{H}_{2} \mathrm{O}_{2}$ in excess, that SOD1 may also indirectly contribute to the increased formation of GSSG, since as reported above it was demonstrated that GPx activity was normal or even increased in EHS self-reporting patients. In fact, whatever the resulting effects of the SOD1 increase in EHS self-reporting patients, it is notable that a similar increased level of SOD1 activity was reported in patients with Alzheimer's disease, with this increased level having been considered for the early diagnosis and therapeutic monitoring of this disease (61). This may also be the case for EMFIS-bearing patients.

During the oxidative process, peroxynitrite $\left(\mathrm{ONOO}^{-}\right)$may also be generated from the reaction of the superoxide anion with nitric oxide in the framework of an oxidative/nitrosative stress process, according to the following formula: $\mathrm{O}_{2}^{-0}+\mathrm{NO} \rightarrow$ ONOO- $^{-}[\mathrm{G}]$.

In this in vivo reaction, the radical coupling of $\mathrm{NO}$ with $\mathrm{O}_{2}^{-}{ }^{-}$to form the non-free radical anion $\mathrm{ONOO}^{-}$is fast enough to outcompete the protective endogenous effect of SOD1.
Although NO is regarded as a physiological cellular regulating agent, due to its rapid intra-tissue diffusion, it is also considered to be a crucial mediator of cellular damage occurring in different inflammation-associated pathological conditions, more particularly in neurodegenerative diseases, including Alzheimer's disease (62). Since NO is produced in large quantities in the brain, it is thought that it may serve a major contributing role in amplifying the peroxynitrite-induced toxicity in the central nervous system, thereby accounting for the fact that Alzheimer's disease is associated with peroxynitrite-associated oxidative stress. In fact, contrary to what was believed in the past, that the majority of oxidative stress-associated toxic effects may be attributed to NO, it is known that in vitro NO may inhibit lipid peroxidation (63); and it is now clearly established that due to the almost instantaneous formation of peroxynitrite each time $\mathrm{NO}$ and superoxide collide, peroxynitrite is the true toxic tissue damaging agent; peroxynitrite is a powerful oxidant that has been proven to cause pathogenic damage by interacting at a relatively slow rate and diffusion-limiting capacity with intracellular lipids, proteins and DNA (62).

A good example of such a selective reaction is the nitration of tyrosine residues in proteins and the formation of NTT, which thereby serves as a marker of peroxynitrite formation (64) and is a marker of oxidative/nitrosative stress (65).

The present study therefore included NTT in the battery of oxidative stress biomarkers used. Considering the overall sample of 60 EHS self-reporting patients investigated, wit was possible to define three categories of patients according to their NTT values: One-third of the patients exhibited values within the normal-range values, and another one-third exhibited values above the upper normal limits, while a further one-third of the patients presented with values below the lower normal limits. Notably, these findings were corroborated by the fact that in the latter two last categories, patients with abnormal mean values, these values were statistically significantly increased or decreased relative to normal values.

These data strongly suggested that one-third of the patients studied, those with statistically significantly increased NTT mean values, presented with detectable oxidative/nitrosative stress in the peripheral blood; overall, these data called into question why two-thirds of the patients presented with normal or statistically significantly decreased NTT values. The increase in NTT values in one-third of the patients may be easily explained by the increased peroxynitrite formation, and also by the fact that a decrease in GSH, usually an efficient scavenger of peroxynitrite (60), may result in a decrease in peroxynitrite detoxification. Furthermore, since SOD1 may also catalyze peroxynitrite-mediated tyrosine nitration (24), it may be hypothesized that the increased SOD1 activity that was identified in a number of patients may also contribute to the increased NTT detection in these patients.

Explaining the normal or decreased NTT values in two-thirds of the patients, however, is more problematic. A plausible hypothesis may be that according to $[\mathrm{F}]$, the increased SOD1 activity may strongly detoxify the organism of superoxide anions, thus decreasing the formation of peroxynitrite to such a level that the NTT may have been normalized or even decreased. If such hypothesis were to be validated, it may further confirm the existence of oxidative 
stress in these patients, since this detoxification process would involve increased SOD1 activity. A second hypothesis may be associated with the scavenging of peroxynitrite by GSH since, as reported above, peroxynitrite is able to directly oxidize low molecular weight thiols, including GSH; this hypothesis is in agreement with the decrease in GSH bioavailability that was observed in the patients. Finally, a third hypothesis may involve the inactivating effects of peroxynitrite on certain enzymes, by inducing the nitration of tyrosine and the oxidation of cysteine. In agreement with the present data, this may be the case for GR in a majority of patients, and for GPX and SOD1 in a number of them, and it may be the case for catalase, according to the data obtained by De Luca et al (57). Tyrosine nitration may indeed affect the structure and function of selective proteins (66), and consequently must be considered to be a central process of peroxynitrite-mediated toxicity. It is notable that tyrosine nitration and, more particularly, GSH depletion, in association with increased peroxynitrite toxicity, has been proposed to contribute to the occurrence and progression of a number of inflammation-associated diseases, particularly the neurodegenerative diseases Parkinson's disease (67), Alzheimer's disease (68) and amyotrophic lateral sclerosis (69). A key molecular mechanism that may account for the occurrence of these pathological disorders may involve the activation of the proinflammatory transcription factor nuclear factor $(\mathrm{NF})-\kappa \mathrm{B}$ by hydrogen peroxide (70) and/or peroxynitrite, possibly through the classical inhibitor of NF- $\kappa \mathrm{B}$ kinase-dependent cell-type specific pathway (71). Further research in this field of molecular biology is required in order to elucidate the molecular causal role of oxidative stress in the onset of inflammation and, more particularly, inflammation-associated disease.

Whatever the precise molecular mechanism to be considered, the present data strongly suggest that EHS self-reporting patients, more precisely EMFIS-bearing patients, present with oxidative/nitrosative stress. This has been evidenced by measuring TBARs, MDA, GSSG/GSH and NTT in the plasma, and the inducible enzymes SOD1 in RBCs and GPx in RBCs and plasma. The search for a correlation between these different parameters confirmed the coherence of the present molecular dissection analysis.

A major finding of the present study was that by using a limited number of oxidative stress biomarkers, $70-80 \%$ of EHS self-reporting patients were able to be characterized by the existence of oxidative stress. Consequently, as is the case for numerous chronic pathological disorders, including cancer (44-47), diabetes (48), cardiovascular diseases $(49,50)$, neurodegenerative diseases (51), and similar pathological syndromes including CFS (51-55) and MCS (57), the present data strongly suggested that EMFIS may be characterized by some degree of chronic inflammation $(3,4)$ in addition to oxidative stress. This means that EMFIS (as for MCS and CFS) is a novel pathological disorder which merits recognition by the international biomedical community and classification as such by the WHO.

There remains no clear explanation as to the causal origin of oxidative stress in EHS self-reporting patients. The hypothesis that a nocebo effect may have been initially causal in the onset of oxidative stress is unlikely, since this is unable to explain the molecular abnormalities that were evident in the present study (4). The hypothesis that certain environmental stressors may be causally implicated in the onset of this pathology requires further investigation. Since it was previously demonstrated that MCS is frequently associated with EHS in EHS self-reporting patients (3), man-made chemicals may theoretically be these environmental stressors. However, in the present study, all patients with MCS that may have been associated with EHS were excluded, thus EMF exposure, as reported by the patients, may be an environmental stressor. This hypothesis merits consideration since numerous in vitro and animal experimental studies have reported that extremely low frequencies (ELF) radiation exposure $(72,73)$, and more importantly radio-frequencies (RF) EMF exposure (74-79), are associated with oxidative stress occurrence, with the resulting biological effects including alterations in differentiation $(72,73)$, inflammatory responses and DNA damage $(77,80)$; all these detrimental effects occur more frequently in the brain (74,76-79).

Finally, it may be concluded that regardless of its causal origin, EMFIS may be biologically characterized as a novel pathological disorder, and thus may be diagnosed in medical practice on the basis of clinical symptoms, and more objectively by measuring: Inflammation-associated biomarkers, including histamine, protein S100B and the cellular stress chaperone proteins Hsp70 and Hsp27 (3); oxidative stress biomarkers, including TBARs, MDA, GSS and NTT in plasma; and antioxidative defense biomarkers, including SOD in RBCs, and GSH and GPx in plasma.

\section{Acknowledgements}

The authors acknowledge Ms. Marie Anne Barros from the Association for Research on Treatment Against Cancer (ARTAC; Paris, France) for clinical assistance, and Dr Natalio Awaida from Labo XV-Paris (Paris, France) for blood collection. The authors also thank Mr. Tony Tweedale from Rebutting Industry Science with Knowledge (RISK) Consultancy for his careful review of the manuscript.

\section{Funding}

The present study was supported by a specific grant (grant no. F13080012) provided by the Osato Research Institute (Gifu, Japan) and by ARTAC, a non-profit private research center (Paris, France; www.artac.info).

\section{Availability of data and materials}

The datasets used and analyzed during the current study are available from the corresponding author on reasonable request.

\section{Authors' contributions}

PI and DB designed the study and developed data collection tools. DB, as principal investigator, led the overall study with respect to data collection, data management, data analysis and interpretation. PI and DC directly provided technical input and guidance for participant selection, data collection, and data analysis and interpretation. DB wrote the manuscript, and PI and DB directly provided critical input to frame and 
finalize the manuscript. All authors read and approved the final manuscript.

\section{Ethics approval and consent to participate}

The present study, part of a therapeutic clinical trial using Fermented Papaya Preparation to treat EHS self-reporting patients (4), was agreed by the European Cancer and Environmental Research Institute (ECERI) scientific/ethical advisory committee, and was conducted according to currently accepted ethical guidelines, including informed written consent approval signed by all patients prior to inclusion. This investigation has been also registered in the European Clinical Trials Database ('EudraCT') under the registration no. 2017-003937-27.

\section{Patient consent for publication}

Not applicable.

\section{Competing interests}

The authors declare that they have no competing interests.

\section{References}

1. WHO (World Health Organization): WHO Fact Sheet No. 296 Electromagnetic Fields and Public Health, Electromagnetic Hypersensitivity. Available from: http://www.who. int/peh-emf/publications/facts/fs296/en/, 2005

2. Hansson Mild K, Repacholi M, van Deventer E and Ravazzani P: Working Group Report. In: roceedings International Workshop on EMF hypersensitivity, 25-27 October 2004, Prague, Czech Republic. In WHO Press, Milan, pp15-26, 2006.

3. Belpomme D, Campagnac C and Irigaray P: Reliable disease biomarkers characterizing and identifying electrohypersensitivity and multiple chemical sensitivity as two etiopathogenic aspects of a unique pathological disorder. Rev Environ Health 30 251-271, 2015.

4. Irigaray P, Garrel C, Houssay C, Mantello P and Belpomme D: Beneficial effects of a Fermented Papaya Preparation for the treatment of electrohypersensitivity self-reporting patients: Results of a phase I-II clinical trial with special reference to cerebral pulsation measurement and oxidative stress analysis. Funct Foods Health Dis 8: 122-144, 2018.

5. Belpomme D, Hardell L, Belyaev I, Burgio E and Carpenter D: Thermal and non-thermal health effects of non-ionizing radiation: An international consensus perspective. Envpol (In press).

6. Bergqvist U and Vogel E (eds): Possible health implications of subjective symptoms and electromagnetic fields. A report prepared by a European group of experts for the European Commission, DGV. Arbete och Hälsa, European Commission DG V, National Institute for Working Life, 1997. https://gupea. ub.gu.se//bitstream/2077/4156/1/ah1997_19.pdf.

7. Santini R, Seigne M, Bonhomme-Faivre L, Bouffet S, Defrasme E and Sage M: Symptoms experienced by users of digital cellular phones: A study of a French engineering school. Electromagn Biol Med 21: 81-88, 2002.

8. Röösli M: Radiofrequency electromagnetic field exposure and non-specific symptoms of ill health: A systematic review. Environ Res 107: 277-287, 2008

9. Baliatsas C, Van Kamp I, Bolte J, Schipper M, Yzermans J and Lebret E: Non-specific physical symptoms and electromagnetic field exposure in the general population: Can we get more specific? A systematic review. Environ Int 41: 15-28, 2012.

10. Hagström M, Auranen J and Ekman R: Electromagnetic hypersensitive Finns: Symptoms, perceived sources and treatments, a questionnaire study. Pathophysiology 20: 117-122, 2013.

11. Irigaray P, Lebar P and Belpomme D: How ultrasonic cerebral tomosphygmography can contribute to the diagnosis of electrohypersensitivity. JUM (In press).
12. Greaves MW and Sabroe RA: Histamine: The quintessential mediator. J Dermatol 23: 735-740, 1996.

13. Kapural M, Krizanac-Bengez LJ, Barnett G, Perl J, Masaryk T, Apollo D, Rasmussen P, Mayberg MR and Janigro D: Serum S-100beta as a possible marker of blood-brain barrier disruption. Brain Res 940: 102-104, 2002.

14. Kanner AA,Marchi N,Fazio V,Mayberg MR,KoltzMT, Siomin V, Stevens GH, Masaryk T, Aumayr B, Vogelbaum MA, et al: Serum S100beta: A noninvasive marker of blood-brain barrier function and brain lesions. Cancer 97: 2806-2813, 2003.

15. Morimoto RI: Cells in stress: Transcriptional activation of heat shock genes. Science 259: 1409-1410, 1993.

16. Santoro MG: Heat shock factors and the control of the stress response. Biochem Pharmacol 59: 55-63, 2000.

17. Lebel B, Arnoux B, Chanez P, Bougeard YH, Daures JP, Bousquet $\mathrm{J}$ and Campbell AM: Ex vivo pharmacologic modulation of basophil histamine release in asthmatic patients. Allergy 51: 394-400, 1996.

18. Smit LH, Korse CM and Bonfrer JM: Comparison of four different assays for determination of serum S-100B. Int J Biol Markers 20: 34-42, 2005.

19. De AK and Roach SE: Detection of the soluble heat shock protein 27 (hsp27) in human serum by an ELISA. J Immunoassay Immunochem 25: 159-170, 2004.

20. Pockley AG, Shepherd J and Corton JM: Detection of heat shock protein 70 (Hsp70) and anti-Hsp70 antibodies in the serum of normal individuals. Immunol Invest 27: 367-377, 1998.

21. Pryor WA: On the detection of lipid hydroperoxides in biological samples. Free Radic Biol Med 7: 177-178, 1989.

22. Sies H: Glutathione and its role in cellular functions. Free Radic Biol Med 27: 916-921, 1999.

23. Radi R: Nitric oxide, oxidants, and protein tyrosine nitration. Proc Natl Acad Sci USA 101: 4003-4008, 2004.

24. Londero D and Lo Greco P: Automated high-performance liquid chromatographic separation with spectrofluorometric detection of a malondialdehyde-thiobarbituric acid adduct in plasma. J Chromatogr A 729: 207-210, 1996.

25. Ohkawa $\mathrm{H}$, Ohishi $\mathrm{N}$ and Yagi K: Assay for lipid peroxides in animal tissues by thiobarbituric acid reaction. Anal Biochem 95: 351-358, 1979.

26. Akerboom TP and Sies H: Assay of glutathione, glutathione disulfide, and glutathione mixed disulfides in biological samples. Methods Enzymol 77: 373-382, 1981.

27. Ischiropoulos H, Zhu L, Chen J, Tsai M, Martin JC, Smith CD and Beckman JS: Peroxynitrite-mediated tyrosine nitration catalyzed by superoxide dismutase. Arch Biochem Biophys 298: 431-437, 1992.

28. Jocelyn PC: Spectrophotometric assay of thiols. Methods Enzymol 143: 44-67, 1987.

29. Marklund S and Marklund G: Involvement of the superoxide anion radical in the autoxidation of pyrogallol and a convenient assay for superoxide dismutase. Eur J Biochem 47: 469-474, 1974.

30. Mannervik B: Measurement of glutathione reductase activity. Curr Protoc Toxicol: May 2001. doi: 10.1002/0471140856. tx0702s00.

31. Günzler WA, Kremers H and Flohé L: An improved coupled test procedure for glutathione peroxidase (EC 1-11-1-9-) in blood. Z Klin Chem Klin Biochem 12: 444-448, 1974.

32. Avery SV: Molecular targets of oxidative stress. Biochem J 434: 201-210, 2011.

33. Holmström KM and Finkel T: Cellular mechanisms and physiological consequences of redox-dependent signalling. Nat Rev Mol Cell Biol 15: 411-421, 2014.

34. Cencioni C, Spallotta F, Martelli F, Valente S, Mai A, Zeiher AM and Gaetano C: Oxidative stress and epigenetic regulation in ageing and age-related diseases. Int J Mol Sci 14: 17643-17663, 2013.

35. Belpomme D: Epigenetics and environmental carcinogenesis: Towards a general free radical theory of cancer. In: World Cancer Congress. Session 202: Cancer Epigenetics and DNA Methylation. Abstract no. 1. Barcelona, Spain, p73, 2017.

36. Beckman JS: Oxidative damage and tyrosine nitration from peroxynitrite. Chem Res Toxicol 9: 836-844, 1996.

37. Ray PD, Huang BW and Tsuji Y: Reactive oxygen species (ROS) homeostasis and redox regulation in cellular signaling. Cell Signal 24: 981-990, 2012.

38. Nielsen F, Mikkelsen BB, Nielsen JB, Andersen HR and Grandjean P: Plasma malondialdehyde as biomarker for oxidative stress: Reference interval and effects of life-style factors. Clin Chem 43: 1209-1214, 1997. 
39. Ayala A, Muñoz MF and Argüelles S: Lipid peroxidation: Production, metabolism, and signaling mechanisms of malondialdehyde and 4-hydroxy-2-nonenal. Oxid Med Cell Longev 2014 360438, 2014.

40. Negre-Salvayre A, Coatrieux C, Ingueneau C and Salvayre R: Advanced lipid peroxidation end products in oxidative damage to proteins. Potential role in diseases and therapeutic prospects for the inhibitors. Br J Pharmacol 153: 6-20, 2008.

41. Pizzimenti S, Ciamporcero E, Daga M, Pettazzoni P, Arcaro A, Cetrangolo G, Minelli R, Dianzani C, Lepore A, Gentile F and Barrera G: Interaction of aldehydes derived from lipid peroxidation and membrane proteins. Front Physiol 4: 242, 2013.

42. Del Rio D, Stewart AJ and Pellegrini N: A review of recent studies on malondialdehyde as toxic molecule and biological marker of oxidative stress. Nutr Metab Cardiovasc Dis 15: 316-328, 2005.

43. Slatter DA, Avery NC and Bailey AJ: Identification of a new cross-link and unique histidine adduct from bovine serum albumin incubated with malondialdehyde. J Biol Chem 279: 61-69, 2004.

44. Gönenç A, Ozkan Y, Torun M and Simșek B: Plasma malondialdehyde (MDA) levels in breast and lung cancer patients. J Clin Pharm Ther 26: 141-144, 2001.

45. Akbulut H, Akbulut KG, Icli F and Büyükcelik A: Daily variations of plasma malondialdehyde levels in patients with early breast cancer. Cancer Detect Prev 27: 122-126, 2003.

46. Manju V, Kalaivani Sailaja J and Nalini N: Circulating lipid peroxidation and antioxidant status in cervical cancer patients: A case-control study. Clin Biochem 35: 621-625, 2002.

47. Bakan E, Taysi S, Polat MF, Dalga S, Umudum Z, Bakan N and Gumus M: Nitric oxide levels and lipid peroxidation in plasma of patients with gastric cancer. Jpn J Clin Oncol 32: 162-166, 2002.

48. Dierckx N, Horvath G, van Gils C, Vertommen J, van de Vliet J, De Leeuw I and Manuel-y-Keenoy B: Oxidative stress status in patients with diabetes mellitus: Relationship to diet. Eur J Clin Nutr 57: 999-1008, 2003

49. Polidori MC, Savino K, Alunni G, Freddio M, Senin U, Sies H, Stahl W and Mecocci P: Plasma lipophilic antioxidants and malondialdehyde in congestive heart failure patients: Relationship to disease severity. Free Radic Biol Med 32: 148-152, 2002

50. Tamer L, Sucu N, Polat G, Ercan B, Aytacoglu B, Yücebilgiç G Unlü A, Dikmengil M and Atik U: Decreased serum total antioxidant status and erythrocyte-reduced glutathione levels are associated with increased serum malondialdehyde in atherosclerotic patients. Arch Med Res 33: 257-260, 2002

51. Delibas N, Ozcankaya R and Altuntas I: Clinical importance of erythrocyte malondialdehyde levels as a marker for cognitive deterioration in patients with dementia of Alzheimer type: A repeated study in 5-year interval. Clin Biochem 35: 137-141, 2002.

52. Logan AC and Wong C: Chronic fatigue syndrome: Oxidative stress and dietary modifications. Altern Med Rev 6: 450-459, 2001.

53. Manuel y Keenoy B, Moorkens G, Vertommen J and De Leeuw I: Antioxidant status and lipoprotein peroxidation in chronic fatigue syndrome. Life Sci 68: 2037-2049, 2001.

54. Vecchiet J, Cipollone F, Falasca K, Mezzetti A, Pizzigallo E, Bucciarelli T, De Laurentis S, Affaitati G, De Cesare D and Giamberardino MA: Relationship between musculoskeletal symptoms and blood markers of oxidative stress in patients with chronic fatigue syndrome. Neurosci Lett 335: 151-154, 2003.

55. Richards RS, Wang L and Jelinek H: Erythrocyte oxidative damage in chronic fatigue syndrome. Arch Med Res 38: 94-98, 2007.

56. Maes M: Inflammatory and oxidative and nitrosative stress pathways underpinning chronic fatigue, somatization and psychosomatic symptoms. Curr Opin Psychiatry 22: 75-83, 2009.

57. De Luca C, Thai JC, Raskovic D, Cesareo E, Caccamo D, Trukhanov A and Korkina L: Metabolic and genetic screening of electromagnetic hypersensitive subjects as a feasible tool for diagnostics and intervention. Mediators Inflamm 2014: 924184, 2014.

58. Aquilano K, Baldelli S and Ciriolo MR: Glutathione: New roles in redox signaling for an old antioxidant. Front Pharmacol 5: 196, 2014.

59. Zitka O, Skalickova S, Gumulec J, Masarik M, Adam V, Hubalek J, Trnkova L, Kruseova J, Eckschlager T and Kizek R Redox status expressed as GSH:GSSG ratio as a marker for oxidative stress in paediatric tumour patients. Oncol Lett 4 : $1247-1253,2012$

60. Briviba K, Kissner R, Koppenol WH and Sies H: Kinetic study of the reaction of glutathione peroxidase with peroxynitrite. Chem Res Toxicol 11: 1398-1401, 1998.
61. Rossi L, Squitti R, Pasqualetti P, Marchese E, Cassetta E Forastiere E, Rotilio G, Rossini PM and Finazzi-Agró A: Red blood cell copper, zinc superoxide dismutase activity is higher in Alzheimer's disease and is decreased by D-penicillamine. Neurosci Lett 329: 137-140, 2002.

62. Pacher P, Beckman JS and Liaudet L: Nitric oxide and peroxynitrite in health and disease. Physiol Rev 87: 315-424, 2007.

63. O'Donnell VB, Chumley PH, Hogg N, Bloodsworth A, Darley-Usmar VM and Freeman BA: Nitric oxide inhibition of lipid peroxidation: Kinetics of reaction with lipid peroxyl radicals and comparison with alpha-tocopherol. Biochemistry 36 : 15216-15223, 1997

64. Ohshima H, Friesen M, Brouet I and Bartsch H: Nitrotyrosine as a new marker for endogenous nitrosation and nitration of proteins. Food Chem Toxicol 28: 647-652, 1990.

65. Ischiropoulos $\mathrm{H}$ : Biological tyrosine nitration: A pathophysiological function of nitric oxide and reactive oxygen species. Arch Biochem Biophys 356: 1-11, 1998.

66. Schopfer FJ, Baker PR and Freeman BA: NO-dependent protein nitration: A cell signaling event or an oxidative inflammatory response? Trends Biochem Sci 28: 646-654, 2003.

67. Marshall KA, Reist M, Jenner P and Halliwell B: The neuronal toxicity of sulfite plus peroxynitrite is enhanced by glutathione depletion: Implications for Parkinson's disease. Free Radic Biol Med 27: 515-520, 1999.

68. Reynolds MR, Berry RW and Binder LI: Site-specific nitration and oxidative dityrosine bridging of the tau protein by peroxynitrite: Implications for Alzheimer's disease. Biochemistry 44: 1690-1700, 2005.

69. Vargas MR, Pehar M, Cassina P, Beckman JS and Barbeito L: Increased glutathione biosynthesis by Nrf2 activation in astrocytes prevents p75NTR-dependent motor neuron apoptosis. J Neurochem 97: 687-696, 2006.

70. Gloire G, Legrand-Poels S and Piette J: NF-kappaB activation by reactive oxygen species: Fifteen years later. Biochem Pharmacol 72: 1493-1505, 2006.

71. Matata BM and Galinanes M: Peroxynitrite is an essential component of cytokines production mechanism in human monocytes through modulation of nuclear factor-kappa B DNA binding activity. J Biol Chem 277: 2330-2335, 2002.

72. Falone S, Grossi MR, Cinque B, D'Angelo B, Tettamanti E, Cimini A, Di Ilio C and Amicarelli F: Fifty hertz extremely low-frequency electromagnetic field causes changes in redox and differentiative status in neuroblastoma cells. Int J Biochem Cell Biol 39: 2093-2106, 2007.

73. Park JE, Seo YK, Yoon HH, Kim CW, Park JK and Jeon S: Electromagnetic fields induce neural differentiation of human bone marrow derived mesenchymal stem cells via ROS mediated EGFR activation. Neurochem Int 62: 418-424, 2013.

74. Consales C, Merla C, Marino C and Benassi B: Electromagnetic fields, oxidative stress, and neurodegeneration. Int J Cell Biol 2012: 683897, 2012.

75. Esmekaya MA, Ozer C and Seyhan N: $900 \mathrm{MHz}$ pulse-modulated radiofrequency radiation induces oxidative stress on heart, lung, testis and liver tissues. Gen Physiol Biophys 30: 84-89, 2011.

76. Kesari KK, Kumar S and Behari J: 900-MHz microwave radiation promotes oxidation in rat brain. Electromagn Biol Med 30: 219-234, 2011.

77. Megha K, Deshmukh PS, Banerjee BD, Tripathi AK, Ahmed R and Abegaonkar MP: Low intensity microwave radiation induced oxidative stress, inflammatory response and DNA damage in rat brain. Neurotoxicology 51: 158-165, 2015.

78. Furtado-Filho OV,Borba JB, Maraschin T, Souza LM,Henriques JA, Moreira JC and Saffi J: Effects of chronic exposure to $950 \mathrm{MHz}$ ultra-high-frequency electromagnetic radiation on reactive oxygen species metabolism in the right and left cerebral cortex of young rats of different ages. Int J Radiat Biol 91: 891-897, 2015.

79. Dasdag S, Akdag MZ, Ulukaya E, Uzunlar AK and Ocak AR: Effect of mobile phone exposure on apoptotic glial cells and status of oxidative stress in rat brain. Electromagn Biol Med 28: 342-354, 2009

80. Simkó M: Cell type specific redox status is responsible for diverse electromagnetic field effects. Curr Med Chem 14: 1141-1152, 2007.

This work is licensed under a Creative Commons

Attribution-NonCommercial-NoDerivatives 4.0 International (CC BY-NC-ND 4.0) License. 